\title{
Elevated preoperative platelet-to- lymphocyte ratio predicts poor prognosis of patients with primary gastrointestinal stromal tumor
}

Wei-Long Chang ${ }^{1,2+}$, Wen-Chang Yang ${ }^{1 \dagger}$, Xiang-Yu Zeng ${ }^{1}$, Cheng-Guo Li $^{1}$, Zhen Xiong ${ }^{1}$, Tao Wang ${ }^{1}$, Rui-Zhi Zhang ${ }^{1}$, Kai-Xiong Tao ${ }^{1}$ and Peng Zhang ${ }^{1 *}$

\begin{abstract}
Background: The neutrophil-to-lymphocyte ratio (NLR) and platelet-to-lymphocyte ratio (PLR) are considered to reflect the systemic inflammatory response and clinical prognosis. However, the independent prognostic values of the NLR and PLR for patients with gastrointestinal stromal tumor (GIST) remain debatable. This study aims to evaluate the prognostic value of preoperative NLR and PLR in GIST patients.

Methods: We retrospectively reviewed all GIST patients diagnosed and surgically treated at Union Hospital between 2005 and 2018. The preoperative NLR and PLR were calculated to evaluate recurrence-free survival (RFS) and overall survival (OS) by Kaplan-Meier analysis. Univariate and multivariate Cox regression analyses were performed to estimate the independent prognostic values.

Results: The median follow-up time was 49 months (interquartile range, 22-74 months). The preoperative PLR was significantly increased in the GIST patients with intermediate and high tumor risks. Increases in the NLR $(\geq 2.34)$ and PLR $(\geq 185.04)$ were associated with shorter RFS and OS $(P<0.01)$. Moreover, the multivariate analysis revealed that elevated PLR was an independent factor for shorter RFS (hazard ratio [HR]: 3.041; 95\% confidence interval [CI]: 2.001-4.622; $P<0.001)$ and OS (HR: 1.899; 95\% Cl: 1.136-3.173; $P=0.014)$.
\end{abstract}

Conclusions: The preoperative PLR is a potential biomarker of GIST and is related to the clinical outcome. An elevated preoperative PLR predicts poor prognosis of patients with primary GIST after complete surgical resection.

Keywords: Gastrointestinal stromal tumor, Neutrophil-to-lymphocyte ratio, Platelet-to-lymphocyte ratio, Inflammatory biomarker, Prognosis

\footnotetext{
* Correspondence: zhangpengwh@hust.edu.cn

'Wei-Long Chang and Wen-Chang Yang are contributed equally to this work.

'Department of Gastrointestinal Surgery, Union Hospital, Tongji Medical College, Huazhong University of Science and Technology, Wuhan 430022, China

Full list of author information is available at the end of the article
}

(c) The Author(s). 2020 Open Access This article is licensed under a Creative Commons Attribution 4.0 International License, which permits use, sharing, adaptation, distribution and reproduction in any medium or format, as long as you give appropriate credit to the original author(s) and the source, provide a link to the Creative Commons licence, and indicate if changes were made. The images or other third party material in this article are included in the article's Creative Commons licence, unless indicated otherwise in a credit line to the material. If material is not included in the article's Creative Commons licence and your intended use is not permitted by statutory regulation or exceeds the permitted use, you will need to obtain permission directly from the copyright holder. To view a copy of this licence, visit http://creativecommons.org/licenses/by/4.0/. The Creative Commons Public Domain Dedication waiver (http://creativecommons.org/publicdomain/zero/1.0/) applies to the data made available in this article, unless otherwise stated in a credit line to the data. 


\section{Background}

Gastrointestinal stromal tumor (GIST) is the most common mesenchymal neoplasm originating from the wall of the gastrointestinal (GI) tract; it accounts for 0.1 to $3 \%$ of all GI tumors and approximately $6 \%$ of all sarcomas [1]. GIST is most commonly located in the stomach $(60 \%)$, followed in order by the small intestine (25\%) and rectum (5\%), and is also occasionally detected in the esophagus, mesentery, omentum and retroperitoneum [2]. Although GIST was once considered a leiomyoma or leiomyosarcoma, it is now distinguished from other mesenchymal tumors because it originates from interstitial cells of Cajal or their precursor cells and possesses a characteristic activating mutation in c-KIT or platelet-derived growth factor receptor $\alpha$ (PDGFRA) [3].

Although complete surgical resection remains a mainstay treatment for localized, primary GIST [4], the 5-year relapse rate is estimated to be $29.5 \%$ [5]. Currently, the tumor mitotic rate, size, location and tumor rupture are considered important independent factors predicting GIST recurrence [6], and postoperative adjuvant tyrosine kinase inhibitor (TKI) treatment may delay recurrence [7]. Therefore, an assessment of the risks of recurrence and progression of GIST has become increasingly important for patients, and studies exploring additional prognostic factors for recurrence risk stratification might increase the prognostic accuracy [8].

Over the last decade, cancer-related inflammation has been clearly established as playing a critical role in promoting tumor progression and metastasis [9]. In fact, inflammatory processes have been evaluated using widely available biomarkers, including macrophage-stimulating protein, C-reactive protein, or other hematological parameters, such as the neutrophil-to-lymphocyte ratio (NLR) or platelet-tolymphocyte ratio (PLR) [10-12]. Among these inflammatory biomarkers, the preoperative blood NLR and PLR are negatively correlated with the prognosis of patients with solid tumors, including colorectal, pancreatic, non-small cell lung and ovarian tumors $[13,14]$. Notwithstanding, investigations of the clinical prognostic value of NLR or PLR for GIST patients are limited and the results remain topic of intense debate $[15,16]$. Regardless, studies including large samples or long-term investigations of the association of the NLR or PLR with outcomes in GIST patients are lacking, and the topic warrants further study.

In the present study, we examined the preoperative NLR and PLR to clarify whether these values are correlated with the clinical outcomes of patients with primary resectable GIST in a Chinese population.

\section{Methods}

\section{Patient population}

Between January 2005 and June 2018, 1082 primary GIST patients were diagnosed at Union Hospital, Tongji Medical College, Huazhong University of Science and Technology, Wuhan, China. According to the modified National Institutes of Health (NIH) consensus [17], 418 (38.6\%) patients were at high risk, $115(10.6 \%)$ at intermediate risk, 309 (28.6\%) at low risk, and 240 (22.2\%) patients at very low risk. The inclusion criteria were listed as follows: (1) without preoperative imatinib therapy, (2) with R0 resection, (3) without distant metastasis, (4) without adjuvant TKI therapy, (5) without clinical symptoms of potential infection, (6) with complete data. Finally, 646 patients were included in this study (Fig. 1). All enrolled patients were diagnosed with GIST relying heavily on CD117 and/or DOG1 immunohistochemical staining. Complete records for blood cell counts, population data and follow-up data were available for all patients. This retrospective study was approved by the Ethics Committee of Tongji Medical College, Huazhong University of Science and Technology. All methods were conducted in accordance with the approved guidelines.

\section{Peripheral blood counts}

Preoperative peripheral blood samples were obtained from all patients within 7 days prior to surgery. No patient had clinical symptoms of an infection at the time of blood sampling. The blood NLR was defined as the absolute neutrophil count in the peripheral blood

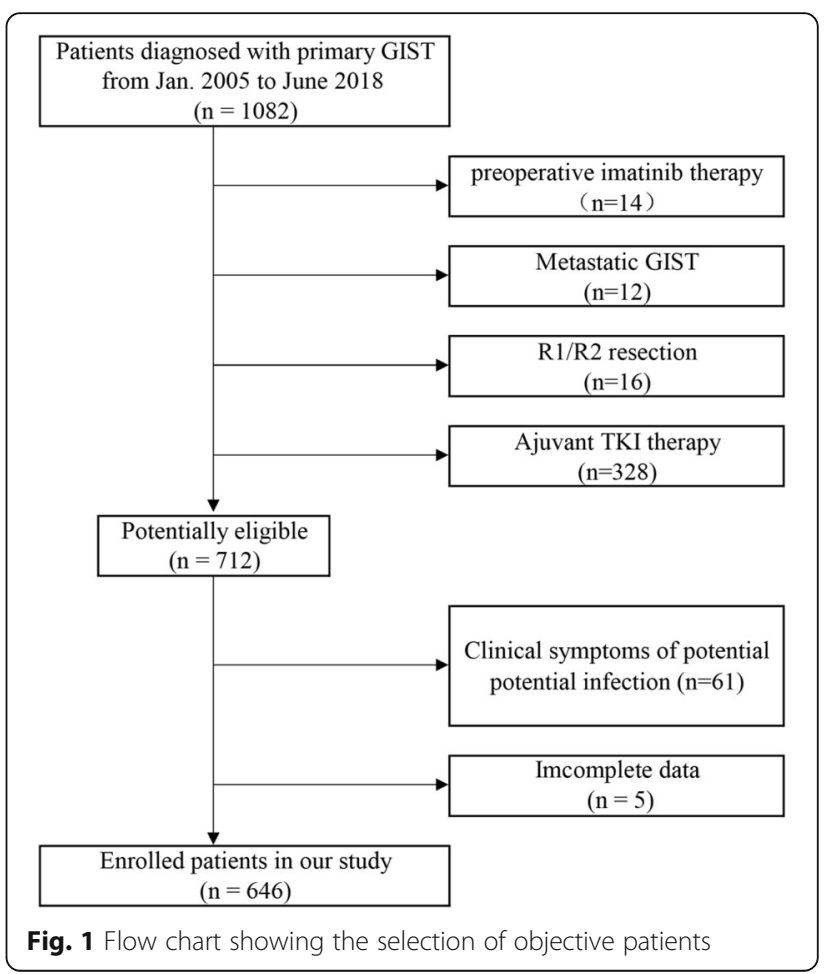


divided by the absolute lymphocyte count. Similarly, the blood PLR was defined as the absolute platelet count in the peripheral blood divided by the absolute lymphocyte count.

A receiver operating characteristic (ROC) curve analysis was performed to determine the cut-off values (with the highest specificity and sensitivity, also called the maximal Youden index) for the NLR and PLR based on the recurrence-free survival (RFS) data to define the high- and low-risk groups (Fig. 2). The high-risk group included patients with an NLR $\geq 2.34$ and PLR $\geq 185.04$.

\section{Data collection}

The detailed clinical characteristics of all patients, including age, sex, tumor size, tumor site, mitotic index, preoperative absolute blood neutrophil count, absolute lymphocyte count, absolute platelet count and treatments received, were collected from the patient records and analyzed in our study.

Follow-up was conducted in the outpatient clinic or by telephone. The site, date and treatment of recurrence were also recorded, and the follow-up duration was calculated from the date of surgery to the date of the last follow-up or death. The data were finally censored at the last follow-up for the living patients.

\section{Statistical analysis}

The summary statistics of the baseline characteristics of all enrolled patients who were, stratified by the NLR or
PLR cut-off values, are reported as frequencies and proportions for categorical variables and as means \pm SD for continuous variables. Categorical data were compared using the chi-square test. Continuous values were compared between two groups using two-tailed Student's ttest or the Wilcoxon-Mann-Whitney U test. Pairwise correlations were evaluated using the two-tailed Pearson test. RFS was calculated as the time in months from tumor resection to pathological or radiological evidence of recurrence. Overall survival (OS) was defined as the time from the date of surgery to the date of death from any cause. Clinical outcomes were evaluated using Kaplan-Meier survival curves, and the groups were compared using the log-rank test. For the calculation of correlations, the NLR and PLR were first divided into dichotomous variables based on the cut-off value. Univariate and multivariate Cox proportional hazard regression models were used to evaluate associations with outcome variables. The level of statistical significance was set to $P<0.05$ for all analyses. All tests were performed using SPSS statistical software (version 25, SPSS Inc., Chicago, IL, USA).

\section{Results}

Six hundred and 46 patients, including 347 males and 299 females, were enrolled in this study cohort. All patients underwent complete surgical resection and refused the postoperative adjuvant imatinib therapy. The median age at diagnosis of the enrolled patients was 60 years

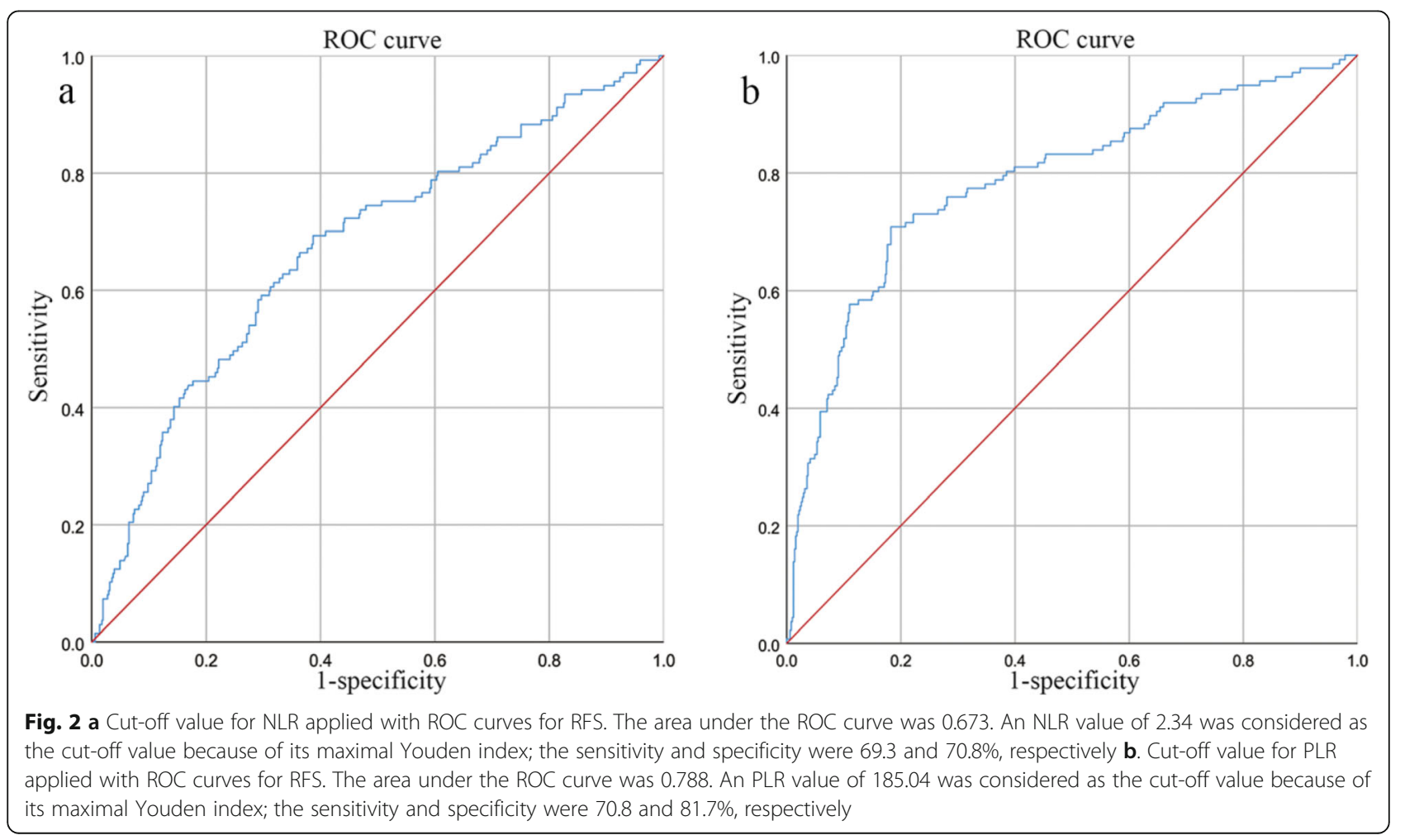


(range, 23-91 years). The most common primary tumor location was the stomach $(61.5 \%)$, followed by the jejunum and ileum (17.0\%), duodenum (10.7\%) and colorectum (5.0\%). The median tumor size was $3.5 \mathrm{~cm}$ (range, $0.6-44 \mathrm{~cm})$, and the median mitotic rate was 3 mitoses per 50 high-power fields (HPFs) (range, 0-51 mitoses). One hundred and 52 patients were at high risk, 71 at intermediate risk, 224 at low risk and 199 at very low risk. The median RFS and OS of the high PLR group were 83 months (95\% confidence interval (CI): 68.697.4) and 124 months (95\% CI: 102.3-145.8), respectively. In addition, the median RFS of the total patients and low PLR group were 144 months (95\% CI: 126.1161.9 ) and 156 months (95\% CI: 133.7-178.3), respectively, and these values failed to reach the median OS.

Table 1 presents a comparison of the baseline demographic and clinicopathological features of the patients dichotomized by the NLR and PLR cut-off values. On the one hand, 354 patients (54.8\%) had a low NLR, and 292 (45.2\%) had a high NLR. A high NLR was significantly associated with the non-stomach location, tumor size and the tumor risk; however, it was not associated with age and the mitotic rate. On the other hand, 456 patients (70.6\%) had a low PLR and 190 (29.4\%) had a high PLR. Different to the findings for the NLR, a high PLR was associated with the non-stomach location, tumor size, the mitotic rate and the tumor risk.

During a median follow-up period of 49 months (interquartile range, $22-74$ months), 43 (12.1\%) patients in the low NLR group and 95 (32.5\%) in the high NLR group experienced recurrence. During the same period, 98 (51.6\%) patients in the high PLR group and $40(8.8 \%)$ in the low PLR group exhibited recurrence. Figure 3 shows the Kaplan-Meier curves for the RFS of the patients with a high or low NLR and PLR, and Fig. 4 shows the KaplanMeier curves for the OS of the patients with a high or low

Table 1 Clinical and pathological features of patients stratified by preoperative NLR and PLR

\begin{tabular}{|c|c|c|c|c|c|c|}
\hline Characteristic & $\begin{array}{l}\text { Low NLR } \\
(<2.34) \\
(n=354)\end{array}$ & $\begin{array}{l}\text { High NLR } \\
(\geq 2.34) \\
(n=292)\end{array}$ & $P$ value & $\begin{array}{l}\text { Low PLR } \\
(<185.04) \\
(n=456)\end{array}$ & $\begin{array}{l}\text { High PLR } \\
(\geq 185.04) \\
(n=190)\end{array}$ & $P$ value \\
\hline Age (years) & $59.4 \pm 11.9$ & $59.2 \pm 11.5$ & 0.852 & $59.5 \pm 11.0$ & $58.7 \pm 13.4$ & 0.456 \\
\hline \multicolumn{7}{|l|}{ Gender } \\
\hline Male & 170 & 177 & 0.020 & 240 & 107 & 0.392 \\
\hline Female & 184 & 115 & & 216 & 83 & \\
\hline \multicolumn{7}{|l|}{ Primary tumor site } \\
\hline Stomach & 245 & 152 & $<0.001$ & 308 & 89 & $<0.001$ \\
\hline Duodenum & 43 & 26 & & 45 & 24 & \\
\hline Small intestine & 32 & 78 & & 56 & 54 & \\
\hline Colorectum & 18 & 14 & & 23 & 9 & \\
\hline Other & 16 & 22 & & 24 & 14 & \\
\hline \multicolumn{7}{|l|}{ Tumor size (cm) } \\
\hline$<5$ & 261 & 158 & $<0.001$ & 325 & 94 & $<0.001$ \\
\hline $5-10$ & 69 & 92 & & 95 & 66 & \\
\hline$>10$ & 24 & 42 & & 36 & 30 & \\
\hline \multicolumn{7}{|l|}{ Unknown } \\
\hline \multicolumn{7}{|c|}{ Mitotic rate (per 50 HPFs) } \\
\hline$\leq 5$ & 313 & 242 & 0.110 & 408 & 147 & $<0.001$ \\
\hline $6-10$ & 31 & 35 & & 38 & 28 & \\
\hline$>10$ & 10 & 15 & & 10 & 15 & \\
\hline \multicolumn{7}{|l|}{ Tumor risk } \\
\hline Very low & 139 & 60 & $<0.001$ & 159 & 40 & $<0.001$ \\
\hline Low & 119 & 105 & & 161 & 63 & \\
\hline Intermediate & 37 & 34 & & 55 & 16 & \\
\hline High & 59 & 93 & & 81 & 71 & \\
\hline
\end{tabular}

Age is reported as mean years \pm SD

NLR neutrophil-to-lymphocyte ratio, PLR platelet-to-lymphocyte ratio, HPF high-power field

Bold values indicate statistical significance at $P<0.05$ 

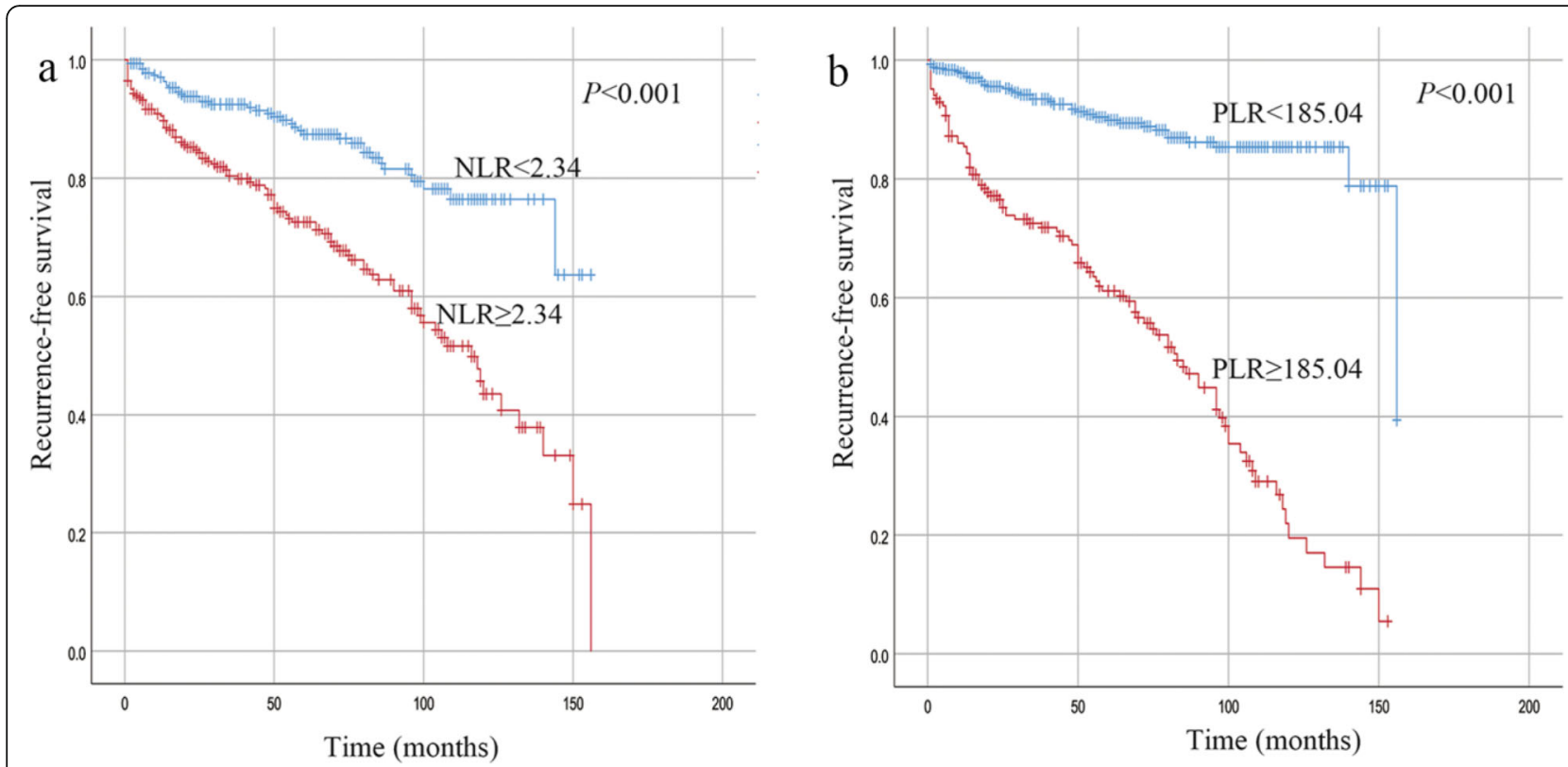

Fig. 3 Kaplan-Meier curves for the RFS of GIST patients stratified according to a high or low NLR $\mathbf{a}$ and PLR $\mathbf{b}$

NLR and PLR. The follow-up data revealed that high preoperative NLR and PLR were both significant factors associated with a poor prognosis $(P<0.001)$. The elevated NLR and PLR suggested inferior RFS in each risk class group $(P<0.05$, Table 2$)$. Furthermore, the elevated PLR suggested inferior OS in the very low/low-risk group and high-risk group $(P<0.001$ and $P=0.008$, respectively; Fig. $5 \mathrm{a}$ and $\mathrm{c})$. In addition, we observed a tendency that an increased level PLR resulted in an unfavorable OS in the intermediate-risk group ( $P=0.067$; Fig. $5 b)$.
Univariate and multivariate survival analyses of RFS and OS were performed to investigate whether the NLR or PLR was associated with clinical outcome. The univariate analysis revealed that a high NLR and high PLR indicated a poor prognosis for the RFS (Table 3) and OS (Table 4). Moreover, a multivariate analysis was performed using the Cox proportional hazards regression model to determine the independent prognostic significance of the NLR or PLR for determining the RFS and OS. The results showed that a high PLR was associated
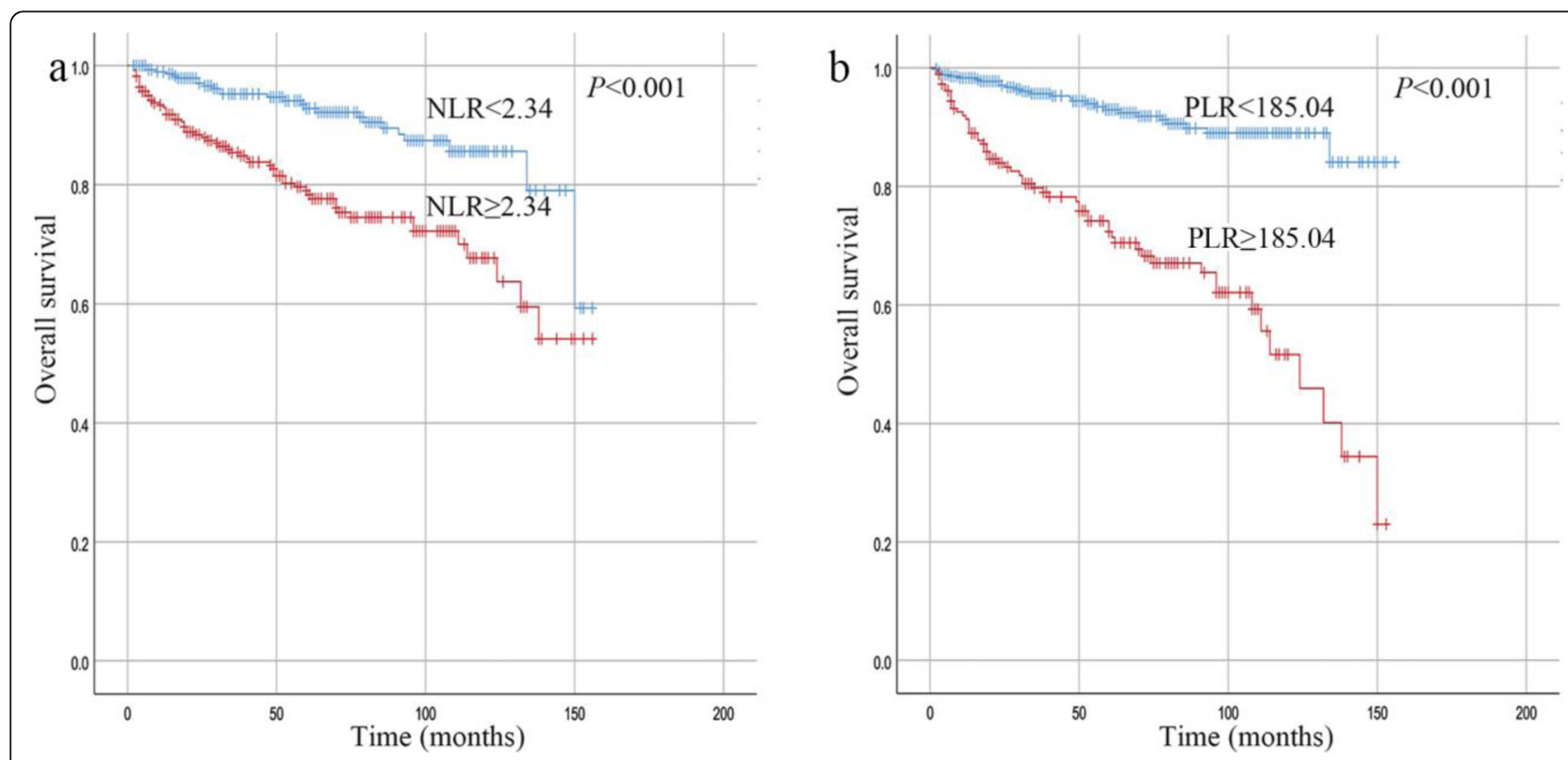

Fig. 4 Kaplan-Meier curves for the OS of GIST patients stratified according to a high or low NLR $\mathbf{a}$ and PLR $\mathbf{b}$ 
Table 2 Prediction of RFS and OS by NLR and PLR in different risk classes

\begin{tabular}{llllll}
\hline Tumor risk & NLR & & & PLR \\
\cline { 2 - 3 } & RFS & OS & & RFS & OS \\
\hline Very low and low & $\boldsymbol{P}=\mathbf{0 . 0 0 3}$ & $\boldsymbol{P}=\mathbf{0 . 0 1 2}$ & & $\boldsymbol{P}<\mathbf{0 . 0 0 1}$ & $\boldsymbol{P}<\mathbf{0 . 0 0 1}$ \\
Intermediate & $\boldsymbol{P}=\mathbf{0 . 0 1 5}$ & $P=0.068$ & & $\boldsymbol{P}<\mathbf{0 . 0 0 1}$ & $P=0.067$ \\
High & $\boldsymbol{P}=\mathbf{0 . 0 3 5}$ & $P=0.125$ & & $\boldsymbol{P}<\mathbf{0 . 0 0 1}$ & $\boldsymbol{P}=\mathbf{0 . 0 0 8}$
\end{tabular}

$N L R$ neutrophil-to-lymphocyte ratio, $P L R$ platelet-to-lymphocyte ratio, $R F S$ recurrence-free survival, $O S$ overall survival

Bold values indicate statistical significance at $P<0.05$

with a shorter RFS (hazard ratio [HR]: 3.041; 95\% CI: 2.001-4.622; $P<0.001$ ) and OS (HR: 1.899; 95\% CI: 1.136-3.173; $P=0.014$ ), as outlined in Tables 3 and 4 . Furthermore, the mitotic rate, tumor size and PLR were determined to be independent prognostic factors for RFS and OS.

\section{Discussion}

Since the Greek physician Claudius Galenus proposed the existence of similarities between tumor and inflammatory tissues approximately 1800 years ago [18], scientists have persistently explored their connections in various tumor types. For GIST patients with specific gene mutations, complete surgical resection and postoperative adjuvant TKI therapy have become the optimal treatment options. However, approximately $60 \%$ of patients relapse within 5 years after surgery [19]. Thus, other risk factors must also be considered to improve treatment decisions and patient outcomes. In particular, increasing evidence supports inflammation and the immune response as playing important roles in GIST [20,21].

The NLR and PLR, biomarkers of the immune response, have been demonstrated to act as prognostic surrogates in various tumor types. However, no unanimous consensus exists for the potential predictive roles of NLR and PLR in GIST. Racz et al. [15] reported a predictive value for the PLR, but not NLR, while Jiang et al. [22] showed that the NLR was an independent prognostic factor. Thus, further investigation is required to probe this interesting question.

In the present study, we evaluated the efficacies of the NLR and PLR as preoperative inflammatory biomarkers in 646 Chinese patients who underwent surgery for

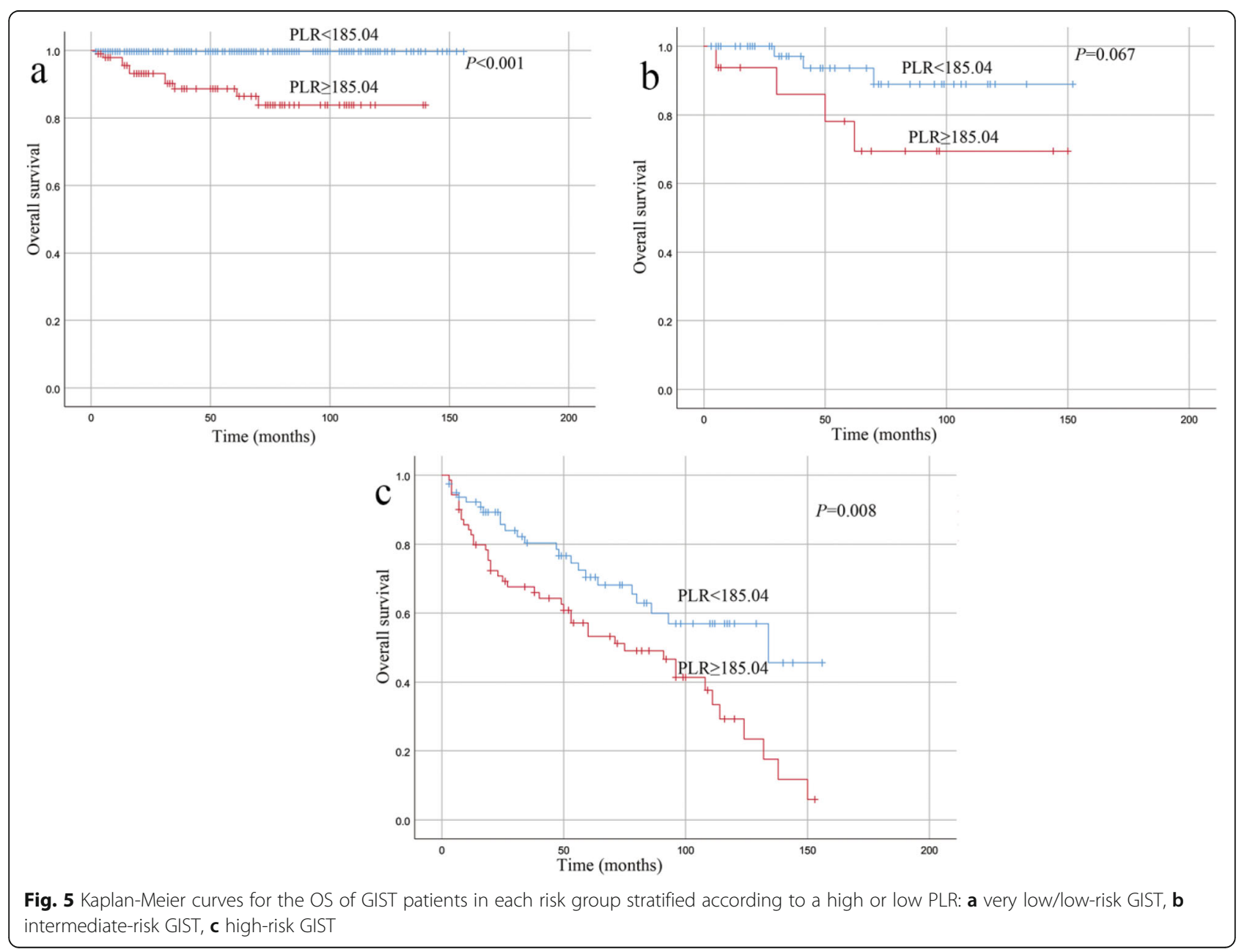


Table 3 Univariate and multivariate analyses to predict RFS

\begin{tabular}{|c|c|c|c|c|}
\hline Variable & Univariate Analysis & & Multivariate Analysis & \\
\hline & $\mathrm{HR}(95 \% \mathrm{Cl})$ & $P$ value & $\mathrm{HR}(95 \% \mathrm{Cl})$ & $P$ value \\
\hline Age (>60y) & $1.025(0.732,1.434)$ & 0.887 & & \\
\hline Gender (male) & $0.993(0.709,1.391)$ & 0.969 & & \\
\hline Location (non-stomach) & $1.926(1.373,2.701)$ & $<0.001$ & $0.965(0.679,1.372)$ & 0.884 \\
\hline Tumor size ( $\geq 5 \mathrm{~cm})$ & $6.666(4.399,10.101)$ & $<0.001$ & $3.228(2.057,5.067)$ & $<0.001$ \\
\hline Mitotic rate $(>5)$ & $8.317(5.805,11.406)$ & $<0.001$ & $4.071(2.825,5.886)$ & $<0.001$ \\
\hline $\operatorname{NLR}(\geq 2.34)$ & $2.737(1.903,3.937)$ & $<0.001$ & $1.302(0.881,1.925)$ & 0.186 \\
\hline PLR ( $\geq 185.04)$ & $6.331(4.364,9.184)$ & $<0.001$ & $3.041(2.001,4.622)$ & $<0.001$ \\
\hline
\end{tabular}

$R F S$ recurrence-free survival, $H R$ hazard ratio, $C l$ confidence interval, $N L R$ neutrophil-to-lymphocyte ratio, $P L R$ platelet-to-lymphocyte ratio Bold values indicate statistical significance at $P<0.05$

primary GIST at our center and did not receive imatinib or sunitinib therapy over an observational period of 13 years. According to our analysis, the modified NIH criteria are valid and reliable for predicting the RFS and OS of Chinese GIST patients. Additionally, our findings provide evidence for the roles of the NLR and PLR as predictors of GIST recurrence. Although our study only revealed associations between the NLR and shorter RFS and OS in GIST patients, our finding is consistent with the results obtained in several other cancers, including hepatocellular carcinoma, cholangiocarcinoma, and colorectal cancer [23-25].

The prognostic role of the preoperative PLR in GIST patients has rarely been investigated until to date. Racz et al. [15] have confirmed the presence of a correlation between a high PLR and reduced RFS in North American patients. In the present study, we observed that a high preoperative PLR was an independent prognostic factor for reduced RFS and OS in primary localized GIST, consistent with the results obtained from patients with other malignant diseases, such as colon cancer and ovarian cancer. Thus, a PLR assessment may enable an accurate prediction of disease recurrence and patient survival after complete resection. Although the exact cause remains unclear, we propose that neutrophils are more sensitive to potential infection or inflammatory factors, which may lead to an NLR bias in GIST patients. In contrast, because the PLR is far more resistant to this effect, it may truly reflect the response to cancer-related inflammation. Furthermore, several inflammatory factors, including IL- 6 and TNF- $\alpha$, may stimulate megakaryocyte proliferation and induce reactive thrombocytosis [26]. Thus, the PLR increases in response to the imbalance in the immune response and impaired anti-tumor activity. In a previous study, the gastric infiltrating regulatory $\mathrm{T}$ cell count positively correlated with the tumor stage of gastric carcinoma, which is a marker of poor prognosis [27]. However, the interaction between peripheral blood cells and intratumor infiltration of immune cells requires further investigation in future studies.

Our study has some limitations. First of all, it was a retrospective study from a single center conducting the surgical management of Chinese GIST patients, although the conclusions have been drawn, prospective and appropriately designed studies are needed to verify the predictive value of these results. Secondarily, the cut-off values in our studies were defined based on a ROC curve

Table 4 Univariate and multivariate analyses to predict OS

\begin{tabular}{|c|c|c|c|c|}
\hline Variable & Univariate Analysis & & Multivariate Analysis & \\
\hline & HR $(95 \% \mathrm{Cl})$ & $P$ value & HR $(95 \% \mathrm{Cl})$ & $P$ value \\
\hline Age (>60y) & $1.116(0.729,1.708)$ & 0.613 & & \\
\hline Gender (male) & $0.841(0.548,1.292)$ & 0.430 & & \\
\hline Location (non-stomach) & $1.875(1.222,2.876)$ & $<0.001$ & $0.951(0.610,1.484)$ & 0.825 \\
\hline Tumor size ( $\geq 5 \mathrm{~cm}$ ) & $7.191(4.172,12.393)$ & $<0.001$ & $3.079(1.695,5.593)$ & $<0.001$ \\
\hline Mitotic rate $(>5)$ & $13.163(8.444,20.520)$ & $<0.001$ & $7.344(4.536,11.892)$ & $<0.001$ \\
\hline $\operatorname{NLR}(\geq 2.34)$ & $2.857(1.792,4.557)$ & $<0.001$ & $1.507(0.910,2.496)$ & 0.111 \\
\hline PLR ( $\geq 185.04)$ & $4.907(3.120,7.718)$ & $<0.001$ & $1.899(1.136,3.173)$ & 0.014 \\
\hline
\end{tabular}

RFS: recurrence-free survival, $\mathrm{HR}$ : hazard ratio, $\mathrm{Cl}$ : confidence interval, NLR: neutrophil-to-lymphocyte ratio, PLR: platelet-to-lymphocyte ratio Bold values indicate statistical significance at $P<0.05$ 
analysis, and are different from other previous studies. Thus, a reasonable cut-off value that is useful for predicting prognosis of GIST patients should be identified for further investigation. In addition, the adjuvant TKI therapy cohort was excluded from this survival analysis because this treatment would significantly prolong the RFS and reduce the risk of recurrence [28]. Therefore, these patients may have a high preoperative NLR or PLR but a long RFS. Despite these limitations, to the best of our knowledge, our study represents a novel evaluation of the prognostic values of the preoperative NLR and PLR, which reflect the systemic inflammatory response, in Chinese patients with this relatively rare and complex disease who have undergone radical resection. A subsequent survival analysis revealed a relationship between these hematological ratios and the clinical prognosis. Unlike previous reports $[15,16]$, our findings indicated that an elevated PLR might serve as an independent predictor of GIST early recurrence and reduced survival; thus, a high PLR appears to be a reliable and strong prognostic predictor that may be used to guide therapy in the Chinese population. Furthermore, the modified $\mathrm{NIH}$ consensus classification performs well at predicting the survival of Chinese patients with GIST.

\section{Conclusions}

In summary, a high PLR is a potential biomarker of GIST associated with a poor clinical prognosis. Due to its simplicity in predicting individual survival, a PLR of greater than 185.04 might independently refine the stratification of patients, indicating the need for more aggressive therapeutic approaches and more rigorous follow-up schedules. Future research conducted in multiple centers is needed to confirm the utility of PLR in predicting the prognosis of GIST patients.

\section{Abbreviations}

Cl: Confidence interval; GI: Gastrointestinal; GIST: Gastrointestinal stromal tumor; HPFs: High-power fields; HR: Hazard ratio; NIH: National Institutes of Health; NLR: Neutrophil-to-lymphocyte ratio; OS: Overall survival; PLR: Platelet-to-lymphocyte ratio; RFS: Recurrence-free survival; ROC: receiver operating characteristic; TKI: Tyrosine kinase inhibitor

\section{Acknowledgements}

We are grateful to the doctors and nurses working at Wuhan Union Hospital for their assistance with this study.

\section{Authors' contributions}

KXT and PZ designed the study and revised the manuscript. WLC and WCY collected the clinical data and drafted the manuscript. XYZ and CGL provided follow-up data. ZX, TW and RZZ performed statistical analyses. All authors read and approved the final manuscript.

\section{Funding}

This study was supported by grants from the National Key Basic Research Program of China (2015CB5540007), the National Science and Technology Major Project (2017YFC0113503), the National Natural Science Foundation of China (No.81572413, 81702386 and 81874184), the Foundation of Independent Innovation Fund of Huazhong University of Science and Technology (2017KFYXJJ230 and 2017KFYXJJ256), the Natural Science
Foundation of Hubei Province (2016CFA100) and the Key Project of Hubei Health Commission (WJ2019Q030). The founders had no role in the study design, data collection and analysis, decision to publish, or preparation of the manuscript.

\section{Availability of data and materials}

The datasets used and analyzed during the current study are available from the corresponding author upon reasonable request.

\section{Ethics approval and consent to participate}

This retrospective study was approved by the Ethics Committee of Tongji Medical College, Huazhong University of Science and Technology. All methods were conducted in accordance with the approved guidelines.

\section{Consent for publication}

Not applicable.

\section{Competing interests}

The authors declare that they have no competing interests.

\section{Author details}

${ }^{1}$ Department of Gastrointestinal Surgery, Union Hospital, Tongji Medical College, Huazhong University of Science and Technology, Wuhan 430022, China. ${ }^{2}$ Department of General Surgery, The First Affiliated Hospital of Zhengzhou University, Zhengzhou 450052, China.

Received: 13 December 2018 Accepted: 15 April 2020

Published online: 22 April 2020

\section{References}

1. Miettinen M, Lasota J. Gastrointestinal stromal tumors [J]. Gastroenterol Clin N Am. 2013;42(2):399-415.

2. Suehara Y, Akaike K, Mukaihara K, Kurisaki-Arakawa A, Kubota D, Okubo T, Mitomi H, Mitani K, Takahashi M, Toda-Ishii M, Kim Y, Tanabe Y, Takagi T, Hayashi T, Mogushi K, Kaneko K, Yao T, Saito T. KCTD12 is negatively regulated by kit in gastrointestinal stromal tumors []]. Oncotarget. 2018; 9(43):27016-26.

3. Serrano-Candelas E, Ainsua-Enrich E, Navinés-Ferrer A, Rodrigues P, GarcíaValverde A, Bazzocco S, Macaya I, Arribas J, Serrano C, Sayós J, Arango D, Martin M. Silencing of adaptor protein SH3BP2 reduces KIT/PDGFRA receptors expression and impairs gastrointestinal stromal tumors growth []]. Mol Oncol. 2018;12(8):1383-97.

4. Hemming ML, Lawlor MA, Zeid R, Lesluyes T, Fletcher JA, Raut CP, Sicinska ET, Chibon F, Armstrong SA, Demetri GD, Bradner JE. Gastrointestinal stromal tumor enhancers support a transcription factor network predictive of clinical outcome [J]. Proc Natl Acad Sci U S A. 2018;115(25):E5746-55.

5. Sanchez-Hidalgo JM, Duran-Martinez M, Molero-Payan R, Rufian-Peña $S$, Arjona-Sanchez A, Casado-Adam A, Cosano-Alvarez A, Briceño-Delgado J. Gastrointestinal stromal tumors: a multidisciplinary challenge [J]. World J Gastroenterol. 2018;24(18):1925-41.

6. Holmebakk T, Hompland I, Bjerkehagen B, Stoldt S, Bruland ØS, Hall KS, Boye K. Recurrence-free survival after resection of gastric gastrointestinal stromal tumors classified according to a strict definition of tumor rupture: a population-based study [J]. Ann Surg Oncol. 2018;25(5):1133-9.

7. Vincenzi B, Nannini M, Badalamenti G, Grignani G, Fumagalli E, Gasperoni S, D'Ambrosio L, Incorvaia L, Stellato M, Spalato Ceruso M, Napolitano A, Valeri S, Santini D, Tonini G, Casali PG, Dei Tos AP, Pantaleo MA. Imatinib rechallenge in patients with advanced gastrointestinal stromal tumors following progression with imatinib, sunitinib and regorafenib [J]. Ther Adv Med Oncol. 2018;10:1758835918794623.

8. Goh BK, Chok AY, Allen JC Jr, Quek R, Teo MC, Chow PK, Chung AY, Ong HS, Wong WK. Blood neutrophil-to-lymphocyte and platelet-to-lymphocyte ratios are independent prognostic factors for surgically resected gastrointestinal stromal tumors [J]. Surgery. 2016;159(4):1146-56.

9. Reinehr T, Roth CL. Inflammation markers in type 2 diabetes and the metabolic syndrome in the pediatric population [J]. Curr Diab Rep. 2018; 18(12):131.

10. Mao T, Li J, Liu L, Zhao W, Liu Y, Gao K, Guo Y, Xie T, Li N, Shi R. Qingchang Wenzhong decoction attenuates DSS-induced colitis in rats by reducing 
inflammation and improving intestinal barrier function via Upregulating the MSP/RON Signalling pathway [J]. Evid Based Complement Alternat Med. 2017;2017:4846876.

11. Wulaningsih W, Holmberg L, Ng T, Rohrmann S, Van Hemelrijck M. Serum leptin, C-reactive protein, and cancer mortality in the NHANES III [J]. Cancer Med. 2016;5(1):120-8.

12. Wade RG, Robinson AV, Lo MCl, Keeble C, Marples M, Dewar DJ, Moncrieff MDS, Peach $\mathrm{H}$. Baseline neutrophil-lymphocyte and platelet-lymphocyte ratios as biomarkers of survival in cutaneous melanoma: a multicenter cohort study [J]. Ann Surg Oncol. 2018; 25(11):3341-9.

13. Templeton AJ, McNamara MG, Šeruga B, Vera-Badillo FE, Aneja P, Ocaña A, Leibowitz-Amit R, Sonpavde G, Knox JJ, Tran B, Tannock IF, Amir E. Prognostic role of neutrophil-to-lymphocyte ratio in solid tumors: a systematic review and meta-analysis. J Natl Cancer Inst. 2014;106(6): dju124.

14. Proctor MJ, Morrison DS, Talwar D, Balmer SM, Fletcher CD, O'Reilly DS, Foulis AK, Horgan PG, McMillan DC. A comparison of inflammation-based prognostic scores in patients with cancer. A Glasgow inflammation outcome study [J]. Eur J Cancer. 2011;47(17):2633-41.

15. Racz JM, Cleghorn MC, Jimenez MC, Atenafu EG, Jackson TD, Okrainec A, Venkat Raghavan L, Quereshy FA. Predictive ability of blood neutrophil-tolymphocyte and platelet-to-lymphocyte ratios in gastrointestinal stromal tumors [J]. Ann Surg Oncol. 2014;22(7):2343-50.

16. Perez DR, Baser RE, Cavnar MJ, Balachandran VP, Antonescu CR, Tap WD, Strong VE, Brennan MF, Coit DG, Singer S, Dematteo RP. Blood neutrophilto-lymphocyte ratio is prognostic in gastrointestinal stromal tumor [J]. Ann Surg Oncol. 2013;20(2):593-9.

17. Joensuu H. Risk stratification of patients diagnosed with gastrointestinal stromal tumor. Hum Pathol. 2008;39(10):1411-9.

18. Trinchieri G. Cancer and inflammation: an old intuition with rapidly evolving new concepts [J]. Annu Rev Immunol. 2012;30:677-706.

19. Boichuk S, Galembikova A, Dunaev P, Micheeva E, Valeeva E, Novikova M, Khromova N, Kopnin P. Targeting of FGF-Signaling Re-Sensitizes Gastrointestinal Stromal Tumors (GIST) to Imatinib In Vitro and In Vivo [J]. Molecules. 2018; 23(10). pii: E2643.

20. Cavnar MJ, Zeng S, Kim TS, Ocuin LM, Balachandran VP, Seifert AM, Greer JB, Popow R, Crawley MH, Cohen NA, Green BL, Rossi F, Besmer P, Antonescu CR, DeMatteo RP. KIT oncogene inhibition drives intratumoral macrophage M2 polarization [J]. J Exp Med. 2013;210(13):2873-86.

21. Tan Y, Garcia-Buitrago MT, Trent JC, Rosenberg AE. The immune system and gastrointestinal stromal tumor: a wealth of opportunities [J]. Curr Opin Oncol. 2015;27(4):338-42.

22. Jiang C, Hu WM, Liao FX, Yang Q, Chen P, Rong YM, Guo GF, Yin CX, Zhang B, He WZ, Xia LP. Elevated preoperative neutrophil-to-lymphocyte ratio is associated with poor prognosis in gastrointestinal stromal tumor patients [J]. Onco Targets Ther. 2016;9:877-83.

23. Gao F, Li X, Geng M, Ye X, Liu H, Liu Y, Wan G, Wang X. Pretreatment neutrophil-lymphocyte ratio: an independent predictor of survival in patients with hepatocellular carcinoma [J]. Medicine (Baltimore). 2015; 94(11):e639.

24. Lin G, Liu Y, Li S, Mao Y, Wang J, Shuang Z, Chen J, Li S. Elevated neutrophil-to-lymphocyte ratio is an independent poor prognostic factor in patients with intrahepatic cholangiocarcinoma [J]. Oncotarget. 2016;7(32): 50963-71.

25. Malietzis G, Giacometti M, Askari A, Nachiappan S, Kennedy RH, Faiz OD, Aziz O, Jenkins JT. A preoperative neutrophil to lymphocyte ratio of 3 predicts disease-free survival after curative elective colorectal cancer surgery [J]. Ann Surg. 2014;260(2):287-92.

26. Ferroni P, Riondino S, Formica V, Cereda V, Tosetto L, La Farina F, Valente MG, Vergati M, Guadagni F, Roselli M. Venous thromboembolism risk prediction in ambulatory cancer patients: clinical significance of neutrophil/ lymphocyte ratio and platelet/lymphocyte ratio [J]. Int J Cancer. 2015;136(5): 1234-40.

27. Perrone $G$, Ruffini $P A$, Catalano V, Spino $C$, Santini $D$, Muretto $P$, Spoto C, Zingaretti C, Sisti V, Alessandroni P, Giordani P, Cicetti A, D'Emidio S, Morini S, Ruzzo A, Magnani M, Tonini G, Rabitti C, Graziano F. Intratumoural FOXP3-positive regulatory T cells are associated with adverse prognosis in radically resected gastric cancer [J]. Eur J Cancer. 2008;44(13):1875-82.
28. Joensuu H, Wardelmann E, Sihto H, Eriksson M, Sundby Hall K, Reichardt A, Hartmann JT, Pink D, Cameron S, Hohenberger P, Al-Batran SE, Schlemmer M, Bauer S, Nilsson B, Kallio R, Junnila J, Vehtari A, Reichardt P. Effect of KIT and PDGFRA mutations on survival in patients with gastrointestinal stromal tumors treated with adjuvant Imatinib: an exploratory analysis of a randomized clinical trial [J]. JAMA Oncol. 2017;3(5):602-9.

\section{Publisher's Note}

Springer Nature remains neutral with regard to jurisdictional claims in published maps and institutional affiliations.
Ready to submit your research? Choose BMC and benefit from:

- fast, convenient online submission

- thorough peer review by experienced researchers in your field

- rapid publication on acceptance

- support for research data, including large and complex data types

- gold Open Access which fosters wider collaboration and increased citations

- maximum visibility for your research: over $100 \mathrm{M}$ website views per year

At BMC, research is always in progress.

Learn more biomedcentral.com/submissions 